Article

\title{
Investigation on the Anaphylaxis and Anti-Digestive Stable Peptides Identification of Ultrasound-Treated $\alpha$-Lactalbumin during In-Vitro Gastroduodenal Digestion
}

\author{
Xumei Wang ${ }^{1}$, Zongcai Tu ${ }^{1,2,3}$, Guangxian Liu ${ }^{4}$, Hui Wang ${ }^{1, *}$, Yueming $\mathrm{Hu}^{1}$ and Tao Huang ${ }^{5}$ \\ 1 State Key Laboratory of Food Science and Technology, Nanchang University, 235 East Nanjing Road, \\ Nanchang 330047, China; 13184579152@163.com (X.W.); tuzc_mail@aliyun.com (Z.T.); \\ huyueming@ncu.edu.cn (Y.H.) \\ 2 National R\&D Center for Freshwater Fish Processing, Jiangxi Normal University, Nanchang 330022, China \\ 3 Engineering Research Center of Freshwater Fish High-Value Utilization of Jiangxi Province, \\ Jiangxi Normal University, Nanchang 330022, China \\ 4 Institute of Food Science and Technology, Jiangxi Academy of Agricultural Sciences, Nanchang 330200, China; \\ Liugx178@163.com \\ 5 College of Food and Pharmaceutical Sciences, Ningbo University, Ningbo 315800, China; \\ huangtao@nbu.edu.cn \\ * Correspondence: wanghui00072@aliyun.com; Tel./Fax: +86-791-8830-5938
}

check for updates

Citation: Wang, X.; Tu, Z.; Liu, G.; Wang, H.; Hu, Y.; Huang, T.

Investigation on the Anaphylaxis and Anti-Digestive Stable Peptides Identification of Ultrasound-Treated $\alpha$-Lactalbumin during In-Vitro Gastroduodenal Digestion. Foods 2021, 10, 2760. https://doi.org/ $10.3390 /$ foods 10112760

Received: 19 October 2021

Accepted: 7 November 2021

Published: 10 November 2021

Publisher's Note: MDPI stays neutral with regard to jurisdictional claims in published maps and institutional affiliations.

Copyright: (c) 2021 by the authors. Licensee MDPI, Basel, Switzerland. This article is an open access article distributed under the terms and conditions of the Creative Commons Attribution (CC BY) license (https:/ / creativecommons.org/licenses/by/ $4.0 /)$.

\begin{abstract}
Our previous studies indicated that ultrasound treatment can increase the anaphylaxis of protein. However, investigation on the anaphylaxis changes of ultrasound-treated $\alpha$-lactalbumin (ALA) during digestion is lacking. The anaphylaxis of ultrasound-treated ALA and its digesta was investigated. The anti-digestive stable peptides were identified by high-resolution mass spectrometry. Ultrasound induced the tertiary structure of ALA to unfold and increased its anaphylaxis. During digestion, the anaphylaxis of both gastric and gastroduodenal digesta was further increased. There are two reasons for this phenomenon. On the one hand, linear epitopes played an important role in affecting anaphylaxis compared with the conformational epitope, and some linear epitopes were still retained on the anti-digestive stable peptides produced after gastroduodenal digestion, resulting in increased anaphylaxis after digestion. On the other hand, the presence of intact ALA molecules after digestion still remained strong anaphylaxis. Compared with the digesta of untreated ALA, the digesta of ultrasound-treated ALA possessed higher anaphylaxis. The results indicated that ultrasound increased the anaphylaxis of ALA during digestion.
\end{abstract}

Keywords: $\alpha$-lactalbumin; ultrasound; in-vitro gastroduodenal digestion; anaphylaxis; anti-digestive stable peptides; high-resolution mass spectrometry

\section{Introduction}

Novel non-thermal food processing technologies are emerging and prospectively maintaining the sensory properties of foodstuff that traditional processing methods such as heating and boiling cannot match [1]. The high-intensity ultrasound technique is specified as a sound wave frequency of $20-100 \mathrm{kHz}$ which is widely applied to microorganism inactivation, components extraction, and cell walls crushing due to its nutrient retention and appreciable acceptability [2]. Recently, ultrasound has also attracted desirable attention for its ability to improve the functional properties (emulsification, foaming properties, and oxidation resistance) of proteins [3,4]. Dong et al. [5]. indicated that the antioxidant activity of ultrasound-processed tropomyosin increases with the prolongation of ultrasound action time. Ultrasound has also drawn the close attention of researchers for its application in protein anaphylactogens [6].

Milk and milk-containing food products are recognized as a necessity in western countries. However, the prevalence of worldwide anaphylactic diseases such as food 
allergy has increased [7]. Among food-induced anaphylaxis, cows' milk allergy (CMA) is an anaphylactic response arising from whey protein such as $\alpha$-lactalbumin (ALA), primarily mediated by IgE, which can arouse cell degranulation, and then trigger diarrhea, gastroduodenal bleeding, asthma, etc. [8,9]. When breastfeeding cannot be achieved, infant formulas based on cows' milk are an indispensable alternative for infant feeding [10]. Population-based studies have manifested that the prevalence of CMA in infants ranges from $2-3 \%$, and that in adults is below $0.5 \%$, indicating infants are more likely to suffer from severe anaphylactic diseases [11,12]. Small milk protein ALA in cows' milk is the main anaphylactogen and a globular protein consisting of 123 amino acids with a molecular weight of $14.4 \mathrm{kDa}$ [13]. Many methods have focused on improving the physicochemical and functional properties of ALA [14-18]. However, limited information is available on the influence of ultrasound treatment on the anaphylaxis potential of ALA.

Comprehending the digestion of protein anaphylactogens has become of particular importance due to digestion playing a significant role in ascertaining the potential anaphylaxis of protein. Meanwhile, the influence of processing technologies on the gastroduodenal digestion of anaphylactic proteins is another factor that deserves to be considered. Given the immature digestive system of infants, infants present a higher incidence rate of CMA than adults $[19,20]$. Therefore, the immature gastroduodenal tract of infants should be taken into account for systematically understanding the digestion of protein anaphylactogens. There is evidence that traditional heat processing contributes to unfolding the structure of ovotransferrin, thus exposing antibody-binding epitopes and increasing anaphylaxis [21]. A contradictory conclusion has been reported that irradiation-induced damage to the structure of ALA is the reason for the reduced anaphylaxis of ALA [17,22]. One potential explanation might be that the intensity of food processing technologies and the stability of proteins result in the susceptibility of antibody-binding epitopes to unfold or damage. Our previous study reported the IgG/IgE-binding properties of ultrasound-treated ovalbumin and discovered that ultrasound could raise anaphylaxis through unfolding its tertiary structure [23]. However, the anaphylaxis changes of ultrasound-treated ALA during in-vitro gastroduodenal digestion are unknown.

Overall, the objective of this study was to research the anaphylaxis changes of ultrasound-treated ALA during in-vitro gastroduodenal digestion in infants and to identify the anti-digestive stable peptides. Considering the unfolding effect of ultrasound on ALA, ALA was treated at the intensity of 50 and $100 \mathrm{~W} / \mathrm{cm}^{2}$. The structural characterization was examined through fluorescence spectroscopy and tricine SDS PAGE. The anaphylaxis was evaluated through indirect competitive enzyme-linked immunosorbent assay (icELISA) and degranulation assay. The digesta was isolated by gel filtration chromatography. Finally, the anti-digestive stable peptides were identified by a high-performance liquid chromatography system coupled to tandem mass spectrometry (LC-MS/MS).

\section{Materials and Methods}

\subsection{Materials}

Bovine ALA (L6010, $\geq 85 \%$ ), sodium glycodeoxycholate (G9910), and sodium taurocholate (S0900000) were obtained from Sigma-Aldrich (St.Louis, MO, USA). 4-(2-Aminoethyl) benzenesulfonyl fluoride hydrochloride (D131214) was purchased from Aladdin (Shanghai, China). Pepsin (P8160, 1:10,000), trypsin (T8150, 1:250), $\alpha$-chymotrypsin (YZ-1134007, 1:1200), and 3, 3', 5, 5'-tetramethylbenzidine (TMB) two-component substrate solution (PR1210) were supplied by Solarbio (Beijing, China). Horseradish peroxidase (HRP)-labeled goat anti-rabbit IgG (BL003A) was from Biosharp (Shenzhen, China). CMA patients' sera (pooled sera including 10 patients) was afforded from Plasma Lab International (Everett, WA, USA). The detailed information of the 10 patients can be found in Supplementary Table S1. HRP-labeled goat anti-human IgE (A9667) was bought from Biocheck (San Francisco, CA, USA). Human ELISA kits for $\beta$-hexosaminidase ( $\beta$-Hex), interleukin 6 (IL-6), and histamine were supplied by Meimian (Yancheng, China). The KU812 cells were obtained from iCell Bioscience (Shanghai, China). 


\subsection{Preparing of Rabbit Anti-ALA IgG}

Male Japanese rabbits (three months, permission number was SCXK (Gan) 20140005) were purchased from Longping (Nanchang, Jiangxi), which were used to prepare polyclonal rabbit anti-ALA IgG. All procedures were authorized by the ethics committee of Nanchang University (approval number 0064257) and were carried out according to Chinese guidelines for animal welfare (GB/T35892-2018). After acclimatizing in an environmentally controlled breeding room for 7 days, the rabbits were intravenously injected with $0.8 \mathrm{mg} / \mathrm{mL}$ of ALA $(1 \mathrm{~mL})$ emulsified with the same volume of Freund's complete adjuvant for the first time. After that, ALA was emulsified by Freund's incomplete adjuvant at 1:1 $(v / v)$, and the subsequent booster immunization was carried out at a 6-day interval with a dose of $0.5 \mathrm{mg}$ per rabbit. After the rabbits were anesthetized, the plasma was collected and the rabbit's anti-ALA IgG serum was separated by centrifuging below $4{ }^{\circ} \mathrm{C}$ and stored at $-80^{\circ} \mathrm{C}$.

\subsection{Ultrasound Treatment}

Considering that ALA accounts for $5 \%$ of milk proteins, bovine ALA was suspended in phosphate buffer ( $\mathrm{pH} 7.4,0.05 \mathrm{~mol} / \mathrm{L}$ ) to a concentration of $1 \mathrm{mg} / \mathrm{mL}$, and $20 \mathrm{~mL}$ of ALA solution was treated at a gradually increased intensity (50 and $100 \mathrm{~W} / \mathrm{cm}^{2}$ ) in an ultrasound processor (Scientz-IID, Ningbo, China) equipped with a $3 \mathrm{~mm}$ microtip probe. The ultrasound treatment was performed for $10 \mathrm{~min}$ with the pulsation of $2 \mathrm{~s}$ on, and $2 \mathrm{~s}$ off. The samples were in ice-bath conditions to ensure the temperature was below $20^{\circ} \mathrm{C}$. Untreated ALA was named ALA-0. Ultrasound-treated ALA at 50 and $100 \mathrm{~W} / \mathrm{cm}^{2}$ were named ALA-50 and ALA-100, respectively. ALA-0, ALA-50, and ALA-100 were collectively referred to as substrate samples. Other milk components (e.g., fats) that could influence the ultrasound treatment of ALA were not investigated in this study.

\subsection{Gastroduodenal Digestion In-Vitro}

To better simulate the physiological parameters of the infant gastroduodenal tract, the digestive behavior of substrate samples was performed by a previous method, with some adaptations [24]. In the process of simulated gastric juice (SGJ) digestion, substrate samples were mixed with $10 \mathrm{~mL}$ of SGJ ( $\mathrm{Ph}=3.0)$ embodied with pepsin $(22.75 \mathrm{U} / \mathrm{mg}$ sample) and $\mathrm{NaCl}(0.15 \mathrm{~mol} / \mathrm{L})$. After performing for $2 \mathrm{~h}$ at $37^{\circ} \mathrm{C}$, the gastric digestive behavior was suspended by monitoring the $\mathrm{pH}$ to 7.0 . Afterward, $10 \mathrm{~mL}$ of simulated duodenal juice (SDJ) was added to digest for $2 \mathrm{~h}$, and the components of SDJ were as follows: $2 \mathrm{mmol} / \mathrm{L}$ of bile salts (sodium glycodeoxycholate and sodium taurocholate), $3.45 \mathrm{U}$ trypsin/mg sample, and $0.04 \mathrm{U}$ chymotrypsin/mg sample. It was stopped by adding $4 \mathrm{mmol} / \mathrm{L}$ of protease inhibitor 4-(2-Aminoethyl) benzenesulfonyl fluoride hydrochloride. Samples were placed below $-20{ }^{\circ} \mathrm{C}$ until used. ALA-0, ALA-50, and ALA-100 digested by SGJ were named ALA-0G, ALA-50G, and ALA-100G, respectively, and ALA-0G, ALA-50G, and ALA-100G were called gastric digesta; ALA-0, ALA-50, and ALA-100 digested by SGJ followed SDJ was denoted as ALA-0D, ALA-50D, and ALA-100D, respectively, and ALA-0D, ALA-50D, and ALA-100D were called gastroduodenal digesta.

\subsection{Structure Analysis after Ultrasound Treatment}

\subsubsection{Fluorescence Spectrophotometer}

The intrinsic fluorescence was analyzed according to a previous report with some modifications [25]. $0.5 \mathrm{mg} / \mathrm{mL}$ of substrate samples, gastric digesta, and gastroduodenal digesta were prepared for intrinsic fluorescence spectra detection by a fluorescence spectrophotometer (Hitachi F-7000, Tokyo, Japan). The excitation wavelength was $280 \mathrm{~nm}$, and the emission spectrum was recorded from $300 \mathrm{~nm}$ to $600 \mathrm{~nm}$, with $2 \mathrm{~nm}$ bandpass filters in both excitation and emission. 


\subsubsection{Analysis of Tricine SDS PAGE}

Tricine SDS PAGE analysis was carried out according to a previous study with some modifications [26]. To detect the pattern of ALA-0, ALA-50, ALA-100, ALA-0G, ALA-50G, ALA-100G, ALA-0D, ALA-50D, and ALA-100D, separating gel (16.5\%), spacer gel (10\%), and stacking gel $(4 \%)$ were prepared for electrophoresis (15 $\mu \mathrm{L}$ of samples were applied) with an initial voltage of $30 \mathrm{~V}(1-2 \mathrm{~h})$ until the indicator entered separating gel, then 100 $\mathrm{V}$ was employed. Following electrophoresis, gels were fixed with fixation fluid $(0.5 \%$ glutaraldehyde in $30 \%$ alcohol) for $30 \mathrm{~min}$ and dyed with coomassie brilliant blue R-250 for $20 \mathrm{~min}$, and finally destained until the background was transparent. The samples' distribution in tricine SDS PAGE gel was transferred to a nitrocellulose membrane for western blotting. The analysis of western blotting was carried out according to a method previously described with some modifications [27].

\subsection{Indirect Competitive ELISA}

The IgG/IgE-binding abilities were analyzed by icELISA with rabbit anti-ALA IgG and CMA patients' sera. Briefly, the incubation circumstance was at $37^{\circ} \mathrm{C}$ for $1 \mathrm{~h}$ and the washing solution was PBST (containing $0.05 \%$ Tween-20). The incubation sequence was as follows: each well of the microplate was coated with $2 \mu \mathrm{g} / \mathrm{mL}$ of native ALA (100 $\mu \mathrm{L} /$ well); $1 \%(w / v)$ of fish gelatin blocking solution $(250 \mu \mathrm{L})$ was blocked; $50 \mu \mathrm{L}$ of rabbit anti-ALA $\operatorname{IgG}(1: 10,000)$ or CMA patients' sera $(1: 20)$ and $50 \mu \mathrm{L}$ of samples were blended in the wells; HRP-labeled goat anti-rabbit IgG (1:5000) or HRP-labeled goat anti-human IgE (1:800) was followed; TMB two-component substrate solution was used for color reaction (15 $\mathrm{min}$ ); sulfuric acid $(2 \mathrm{~mol} / \mathrm{L})$ was added to stop the reaction. The binding rate was calculated following the equation previously described [28]. The inhibition rate was calculated as:

$$
\text { The inhibition rate }(\%)=\frac{B_{0}-B}{B_{0}-B_{c}} \times 100 \%
$$

where $B$ and $B_{0}$ are the OD values with and without samples, respectively. $B_{c}$ was the OD values without rabbit anti-ALA IgG or CMA patients' sera. IC50 is the concentration of samples that causes a $50 \%$ inhibition of $\operatorname{IgG}$ recognition $(\mu \mathrm{g} / \mathrm{mL})$. Each sample was performed in triplicate.

\subsection{Degranulation Assay in KU812 Cells}

The KU812 cells were maintained in the medium RPMI-1640, which contained $10 \%$ of fetal bovine sera and $105 \mathrm{U} / \mathrm{L}$ of penicillin/streptomycin. The culture condition was $37^{\circ} \mathrm{C}$ with $\mathrm{CO}_{2}(5 \%)$. The sensitizing condition was as follows: KU812 cells were activated by $10 \mu \mathrm{L}$ of patients' sera $(24 \mathrm{~h})$; then $100 \mu \mathrm{L} /$ well of samples $(0.5 \mathrm{mg} / \mathrm{mL})$ were added for activation ( $3 \mathrm{~h}$ ). The degranulation assay (the release of $\beta-\mathrm{Hex}$, IL- 6 , and histamine) was analyzed by ELISA assays, following the instruction of commercial kits.

\subsection{Gel Filtration Chromatography Isolation}

Gastroduodenal digesta were isolated according to the previous study with some modifications [29]. Freeze-dried ALA-0D and ALA-100D were dissolved in ultrapure water $(2 \mathrm{~mL})$. After being filtered through nylon filter membrane $(0.45 \mathrm{~mm})$, ALA-0D and ALA-100D were loaded onto Sephadex G-25 column $(\Phi 16 \mathrm{~mm} \times 50 \mathrm{~cm})$. An HD-21-88 ultraviolet detector (QiTe, Shanghai, China) coupled with an automatic fraction collector (QiTe, Shanghai, China) was used. The isolated condition was as follows: the eluent was ultrapure water; the flow rate was $0.4 \mathrm{~mL} / \mathrm{min}$; the elution solution was collected every $8 \mathrm{~min}$; the detected wavelength was $220 \mathrm{~nm}$; the detection sensitivity was $0.5 \mathrm{~A}$.

\subsection{Identification of Anti-Digestive Stable Peptides by HPLC-MS/MS}

The anti-digestive stable peptides were identified by HPLC-Orbitrap Q-Exactive HF mass spectrometer (Thermo Fisher Scientific, Waltham, MA, USA). The HPLC condition was as following: the analytical column was AcclaimR PepMap RSLC $(50 \mu \mathrm{m} \times 15 \mathrm{~cm}$, 
C18, $2 \mu \mathrm{m}, 100 \AA$ A); the flow rate was $220 \mathrm{nl} / \mathrm{min}$; the mobile phase was $0.1 \%$ formic acid of aqueous solution (A) and $0.1 \%$ formic acid of acetonitrile solution (B); the gradient condition was set to $0 \min (96 \% \mathrm{~A}, 4 \% \mathrm{~B}), 2 \mathrm{~min}(88 \% \mathrm{~A}, 12 \% \mathrm{~B}), 25 \mathrm{~min}(78 \% \mathrm{~A}, 22 \%$ B), $32 \min (68 \% \mathrm{~A}, 32 \% \mathrm{~B}), 37 \mathrm{~min}(25 \% \mathrm{~A}, 75 \% \mathrm{~B}), 40 \mathrm{~min}(25 \% \mathrm{~A}, 75 \% \mathrm{~B})$. The MS/MS condition was as follows: automatic switching between MS and MS/MS scans used the top-20 method; the scanning range was limited to $350-1650 \mathrm{~m} / \mathrm{z}$; peptide fragmentation was performed via higher-energy collision dissociation (HCD). The parent ion map was analyzed by Xcalibur software. Bos taurus Reference Database (Proteome ID: UP000009136) was used.

\section{Results and Discussion}

\subsection{Structural Characterization}

\subsubsection{Structure of Ultrasound-Treated ALA}

Aromatic amino acids in ALA, especially tryptophan, are the basis of intrinsic fluorescence. The intrinsic fluorescence spectra evolution during ultrasound treatment of ALA was analyzed, due to the appropriability of intrinsic fluorescence spectra for investigating the tertiary structure changes in proteins. The fluorescence emission intensity was detected at a wavelength range of $200-600 \mathrm{~nm}$. When excited at $280 \mathrm{~nm}$, ALA-0 presented a fluorescence emission maximum ( $\lambda$ max) at $346 \mathrm{~nm}$ (Figure 1A). ALA-50 and ALA-100 displayed an increase in fluorescence intensity at the same $\lambda$ max with an increase in ultrasound intensity. The results indicated that ultrasound could induce the tertiary structure of ALA unfolding and expose aromatic amino acids, thus enhancing the fluorescence intensity. A similar phenomenon was observed by Shao et al. [30].
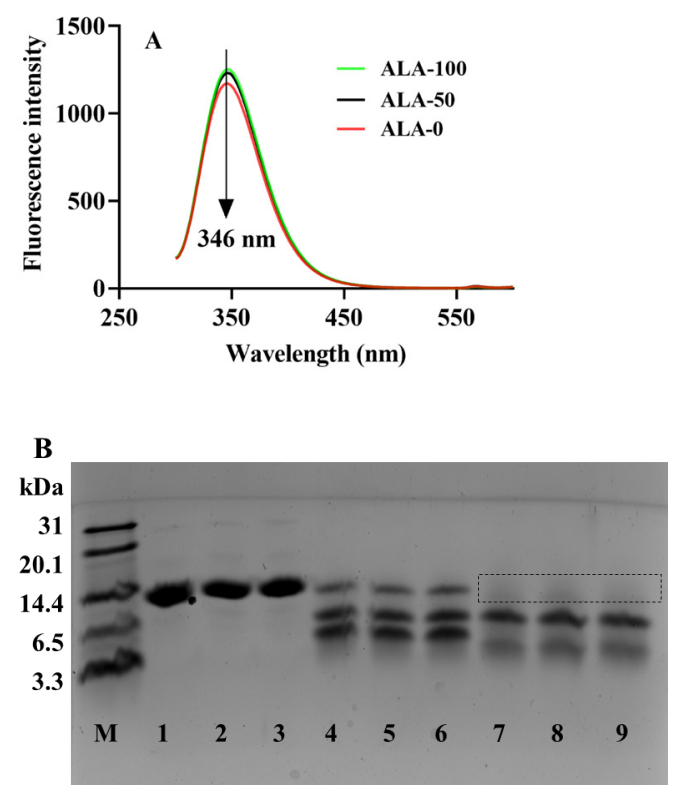

Figure 1. Influence of ultrasound on intrinsic fluorescence spectra of samples (A); the tricine SDS PAGE pattern (B) of ALA-0 (Lane 1), ALA-50 (Lane 2), ALA-100 (Lane 3), ALA-0G (Lane 4), ALA-50G (Lane 5), ALA-100G (Lane 6), ALA-0D (Lane 7), ALA-50D (Lane 8), and ALA-100D (Lane 9). ALA-0: untreated ALA, ALA-50: ultrasound-treated ALA at $50 \mathrm{~W} / \mathrm{cm}^{2}$, ALA-100: ultrasound-treated ALA at $100 \mathrm{~W} / \mathrm{cm}^{2}$. ALA-0G, ALA-50G, and ALA-100G: ALA-0, ALA-50, and ALA-100 digested by simulated gastric juice. ALA-0D, ALA-50D, and ALA-100D: ALA-0, ALA-50, and ALA-100 digested by simulated gastric juice followed simulated duodenal juice.

The molecular weight distribution of samples obtained from the tricine SDS PAGE pattern is outlined in Figure 1B. Obvious bands of ALA-0, ALA-50, and ALA-100 approaching 14.4 kDa were visible (Lanes 1-3 in Figure 1B), and the three bands (Lanes 1-3) had a similar migration distance. No major changes of lanes 1-3 were discovered in the tricine 
SDS PAGE pattern, revealing ultrasound treatment could not cause ALA aggregate to polymers or degrade to low-molecular-weight products [31]. Therefore, combined with the analysis of intrinsic fluorescence spectra, after ultrasound treatment, the tertiary structure of ALA was unfolded but the primary structure was not destroyed.

\subsubsection{Structure Characteristic of Ultrasound-Treated ALA during Gastroduodenal Digestion In-Vitro}

To investigate the variation in the structure of ALA after gastric/gastroduodenal digestion, ALA-0G, ALA-50G, ALA-100G, ALA-0D, ALA-50D, and ALA-100D was analyzed by tricine SDS PAGE (Lanes 4-9 in Figure 1B). In comparison to substrate samples, pepsin hydrolysis caused the tricine SDS-PAGE pattern of gastric digesta (Lanes 4-6 in Figure 1B) to form three hydrolysis fragments (distributed in 3.3-14.4 kDa), implying that the tertiary and primary structure of ALA was destroyed under simulated gastric digestion. The band that appeared near 14.4 kDa was completely undigested ALA. This observation confirmed that ALA was not completely digested because of the simulated immature gastric environment of infants [32]. Three bands were also discovered in ALA-0D, ALA-50D, and ALA-100D (Lanes 7-9 in Figure 1B), and the one near $3.3 \mathrm{kDa}$ was smeared. This might account for further hydrolysis induced by trypsin and $\alpha$-chymotrypsin accelerating the digestion of ALA-0D, ALA-50D, and ALA-100D, causing them to become loose and form small peptide fragments. Therefore, we suggested that gastric digestion destroyed the tertiary and primary structure of ALA-0, ALA-50, and ALA-100, and gastroduodenal digestion further damaged their tertiary and primary structure.

\subsection{IgG/IgE-Binding Abilities and Western Blotting}

ALA is a major whey protein anaphylactogen that can bind with anaphylactic ALAspecific IgG/IgE, leading to various food anaphylactic symptoms. The IgG/IgE-binding abilities of substrate samples, gastric and gastroduodenal digesta were evaluated by icELISA and shown in Figure 2. Figure 2A shows the IgG IC 50 value of ALA-50 and ALA-100 shifting to 50.07 and $44.63 \mu \mathrm{g} / \mathrm{mL}$, respectively. However, the IgG IC 50 value of ALA-0 was $52.99 \mu \mathrm{g} / \mathrm{mL}$. Comparatively, 1.19 folds of the IgG IC 50 value were observed when ALA was treated with the ultrasound intensity of $100 \mathrm{~W} / \mathrm{cm}^{2}$. These results indicated that ultrasound unfolded the tertiary structure of ALA, and exposed the IgG-binding epitopes, resulting in increased anaphylaxis [23]. Furthermore, with the increase of ultrasound intensity, the tertiary structure of ALA gradually unfolded and exposed more IgG-binding epitopes, leading to higher anaphylaxis.

The IgG IC 50 value of gastric digesta tended toward reduced values (increased anaphylaxis), compared with the substrate samples. The IgG IC 50 value of ALA-0G was $38.27 \mu \mathrm{g} / \mathrm{mL}$, and that of ALA-50G and ALA-100G successively declined when the ultrasound intensities were increased to $50(33.15 \mu \mathrm{g} / \mathrm{mL}, 1.15$ folds $)$, and $100 \mathrm{~W} / \mathrm{cm}^{2}$ $(32.00 \mu \mathrm{g} / \mathrm{mL}, 1.20$ folds), indicating an increase of IgG-binding ability in ALA-50G and ALA-100G. The tertiary structure of gastric digesta was destroyed after digestion (Figure 1B), so the conformational epitopes were destroyed. However, compared with the substrate samples, the anaphylaxis was enhanced in the gastric digesta, which probably explained that linear epitopes played a more important role in affecting the anaphylaxis of ALA, compared with the conformational epitopes. Furthermore, the presence of intact ALA molecules after digestion still remained strong anaphylaxis. Gazme et al. [33] showed that the in-vitro digestion caused the egg white proteins to remain residual immune-reactivity due to the presence of intact proteins such as lysozyme. The IgG IC 50 value of ALA-0D $(24.39 \mu \mathrm{g} / \mathrm{mL})$, ALA-50D $(24.65 \mu \mathrm{g} / \mathrm{mL})$, and ALA-100D $(21.13 \mu \mathrm{g} / \mathrm{mL})$ was reduced again, and ALA-100D was reduced dramatically, with the highest anaphylaxis. 

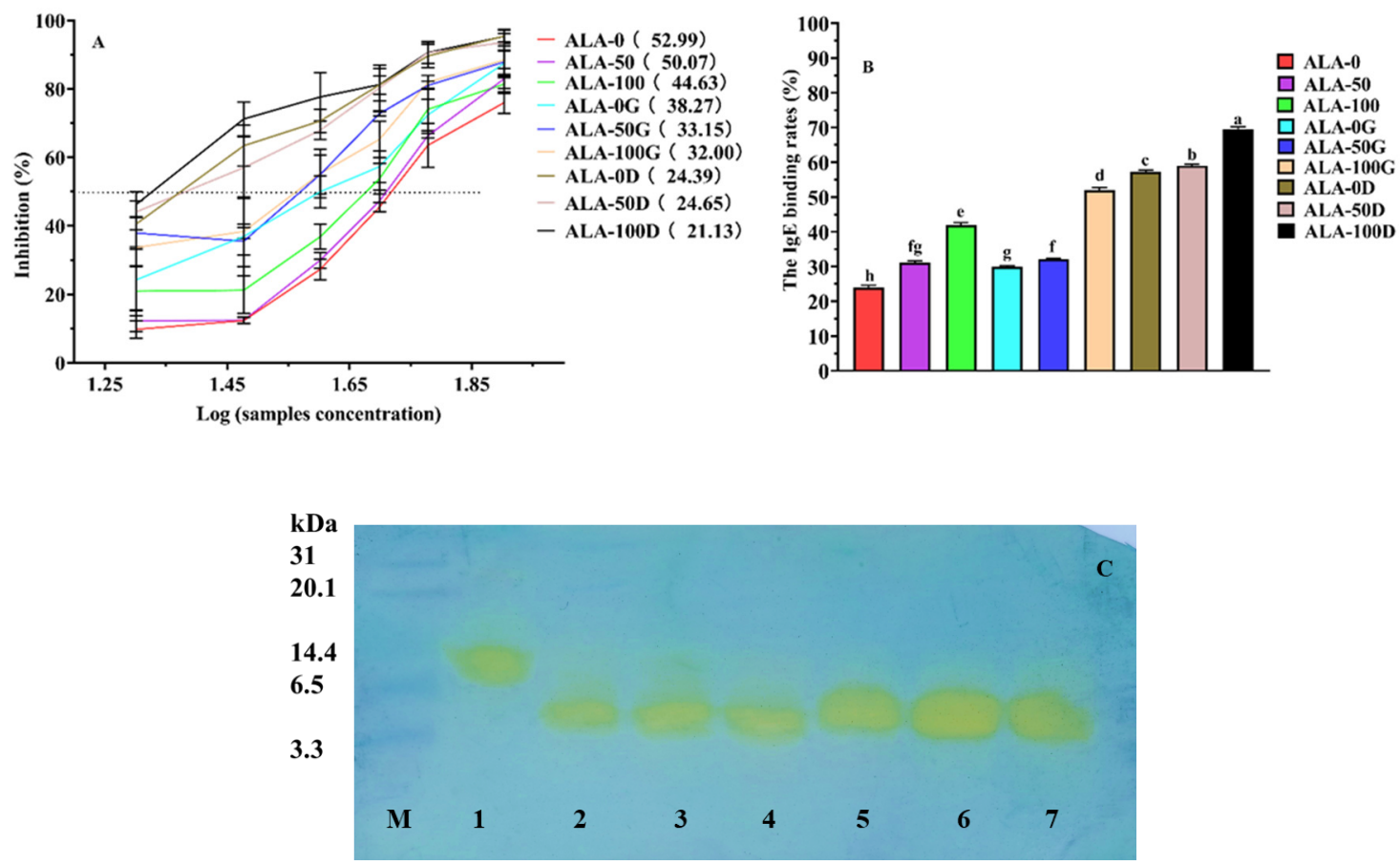

Figure 2. The $\operatorname{IgG}(\mathbf{A})$ and $\operatorname{IgE}(\mathbf{B})$ binding abilities of ALA treated by ultrasound during in-vitro gastric and gastroduodenal digestion determined by icELISA. Rabbit anti-ALA IgG was incubated separately with 20, 30, 40, 50, 60, $80 \mu \mathrm{g} / \mathrm{mL}$ substrate samples, gastric and gastroduodenal digesta. Letters $(\mathrm{a}-\mathrm{g})$ demonstrate significant differences $(p<0.05)$. Western blotting pattern (C) of ALA-0 (Lane 1), ALA-0G (Lane 2), ALA-50G (Lane 3), ALA-100G (Lane 4), ALA-0D (Lane 5), ALA-50D (Lane 6), and ALA-100D (Lane 7). The molecule weight distribution of marker (M) ranges from 3.3 to $31 \mathrm{kDa}$. IgG: immunoglobulin G, IgE: immunoglobulin E. ALA-0: untreated ALA, ALA-50: ultrasound-treated ALA at $50 \mathrm{~W} / \mathrm{cm}^{2}$, ALA-100: ultrasound-treated ALA at $100 \mathrm{~W} / \mathrm{cm}^{2}$. ALA-0G, ALA-50G, and ALA-100G: ALA-0, ALA-50, and ALA-100 digested by simulated gastric juice. ALA-0D, ALA-50D, and ALA-100D: ALA-0, ALA-50, and ALA-100 digested by simulated gastric juice followed simulated duodenal juice.

Figure 2B showed the IgE-binding rates of the nine samples mentioned above, sharing similar trends such as the IgG-binding abilities. In general, the anaphylaxis of the substrate samples increased with the increase of ultrasound intensity, and the anaphylaxis of the gastric and gastroduodenal digesta was further increased, especially for gastroduodenal digesta. ALA-100, ALA-100G, and ALA-100D showed the highest IgE binding rates in substrate samples, gastric digesta, and gastroduodenal digesta $(p<0.05)$, respectively. Guimaraes et al. [34] found that Cry1 Ab protoxin still conserved its immunoreactivity during digestion.

Western blotting was executed to intuitively evaluate the IgG-binding abilities of ALA0, ALA-0G, ALA-50G, ALA-100G, ALA-0D, ALA-50D, and ALA-100D, using self-made rabbit anti-ALA IgG (1:1000 dilution). HRP-labeled goat anti-rabbit IgG was diluted to 1:1000. Given the fact that the anaphylaxis of protein anaphylactogens increased after ultrasound treatment, only gastric and gastroduodenal digesta were embodied for western blotting analysis [30]. As shown in Figure 2C, in comparison with line 1 (ALA-0), lines 2-7 (ALA-0G, ALA-50G, ALA-100G, ALA-0D, ALA-50D, and ALA-100D) also bound with rabbit anti-ALA IgG, showing both digesta had strong anaphylaxis.

\subsection{Bioactive Mediators Release Activity}

ALA would combine with fragment crystallizable $(\mathrm{Fc})$ of the specific IgE that binds to the high-affinity IgE receptor FceRI of mast cells or basophils during the effector phase, arousing cell degranulation and bioactive mediators, such as histamine, IL-6, and $\beta$ Hex generating, resulting in diarrhea, gastroduodenal bleeding, and other anaphylactic symptoms [35]. To investigate the influence of ultrasound on the release of bioactive 
mediators of ALA-0, ALA-50, ALA-100, and their digesta, KU812 cells were applied in the experiment. After the experimental KU812 cells were sensitized with CMA patients' sera, FceRI, a high-affinity IgE receptor that was believed to be closely related to cell degranulation, was expressed on the KU812 cells surface. The cells were then in contact with ALA-0, ALA-50, ALA-100, and their digesta, releasing bioactive mediators.

Panels A, B, and C of Figure 3 show, respectively, the release of $\beta-H e x$, IL-6, and histamine of substrate samples, as well as those of their gastric and gastroduodenal digesta. Stimulating with ALA- 0 caused KU812 cell degranulation, resulting in the release of $\beta$-Hex $(3.33 \mathrm{pg} / \mathrm{mL}$ ). Dramatically, ultrasound-treated ALA (ALA-50, ALA-100) showed increased degranulation ability and led to the increased release of $\beta$-Hex, demonstrating that the anaphylaxis was boosted via ultrasound treatment (Figure 3A). The results were consistent with the IgG/IgE-binding abilities analysis, which was due to the unfolded tertiary structure of ALA treated by ultrasound, leading to epitopes exposure. Besides, when simulated gastric digestion was carried out, the $\beta$-Hex release of gastric digesta were in the rank of ALA-0G $(3.11 \mathrm{pg} / \mathrm{mL})<$ ALA-50G $(3.48 \mathrm{pg} / \mathrm{mL})<$ ALA-100G $(4.19 \mathrm{pg} / \mathrm{mL})$, of which could also be authenticated in gastroduodenal digesta, increased release of $\beta$-Hex was discovered in the digesta of ultrasound-treated ALA. A similar phenomenon could be found in the release of IL-6 and histamine (Figure 3B,C). In general, the anaphylaxis of ultrasoundtreated ALA was strengthened. We hypothesized the reason was that ultrasound unfolded the tertiary structure of ALA and exposed increased antibody-binding epitopes, thus promoting cell degranulation. The anaphylaxis of both the gastric/gastroduodenal digesta of ultrasound-treated ALA was still higher, compared with the gastric/gastroduodenal digesta of untreated ALA, further confirming that ultrasound increased the anaphylaxis of ALA during digestion.
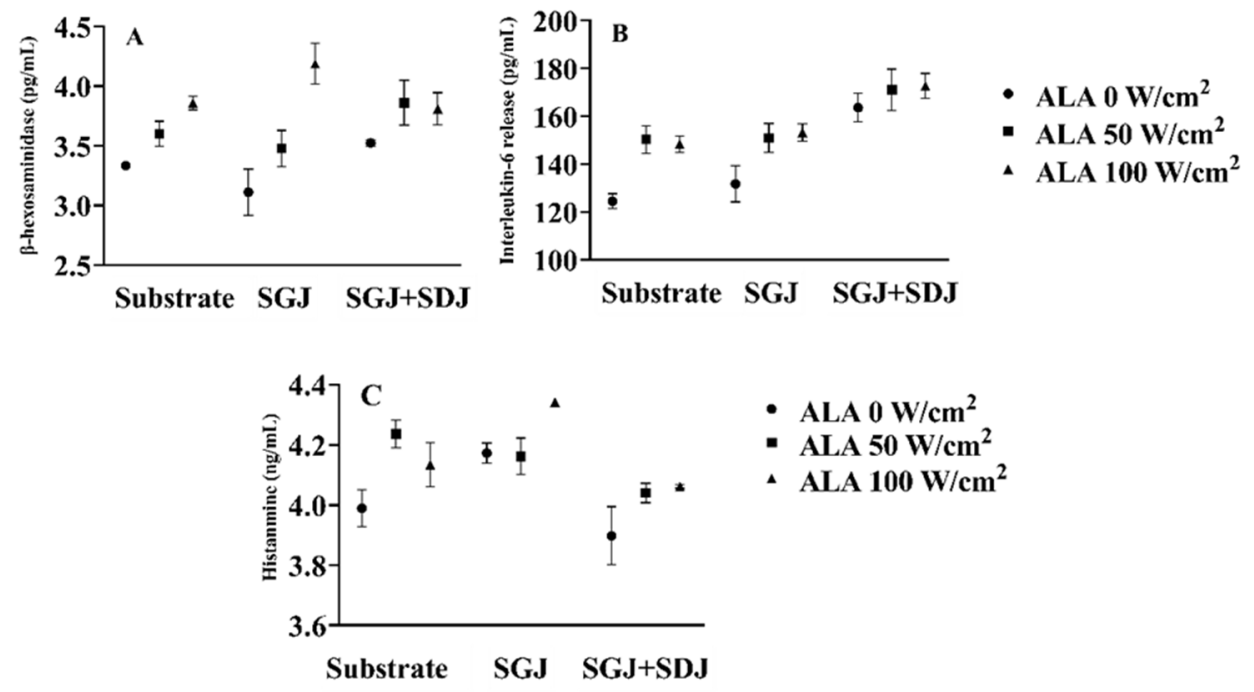

Figure 3. Influence of ultrasound treatment on the release of bioactive mediators. The release of $\beta-\operatorname{Hex}(\mathbf{A})$, the release of IL-6 (B), and the release of histamine (C). Substrate includes ALA-0, ALA50, and ALA-100; SGJ is gastric digesta including ALA-0G, ALA-50G, and ALA-100G; SGJ+SDJ is gastroduodenal digesta containing ALA-0D, ALA-50D, and ALA-100D. SGJ: simulated gastric juice, SDJ: simulated duodenal juice. ALA-0: untreated ALA, ALA-50: ultrasound-treated ALA at $50 \mathrm{~W} / \mathrm{cm}^{2}$, ALA-100: ultrasound-treated ALA at $100 \mathrm{~W} / \mathrm{cm}^{2}$. ALA-0G, ALA-50G, and ALA100G: ALA-0, ALA-50, and ALA-100 digested by simulated gastric juice. ALA-0D, ALA-50D, and ALA-100D: ALA-0, ALA-50, and ALA-100 digested by simulated gastric juice followed simulated duodenal juice.

\subsection{Isolation and Anaphylaxis Analysis of Gastroduodenal Digesta Groups}

We found that gastric/gastroduodenal digesta still had strong anaphylaxis, especially for ALA-100D. We therefore took ALA-100D as an example to isolate by gel filtration chromatography. ALA-0D and ALA-100D were isolated by the Sephadex G-25 column 
(Figure 4). Based on $\mathrm{A}_{220}$, the chromatogram was divided into three groups (I, II, and III), and the molecular weight of the three groups followed the order: group I > group II > group III.
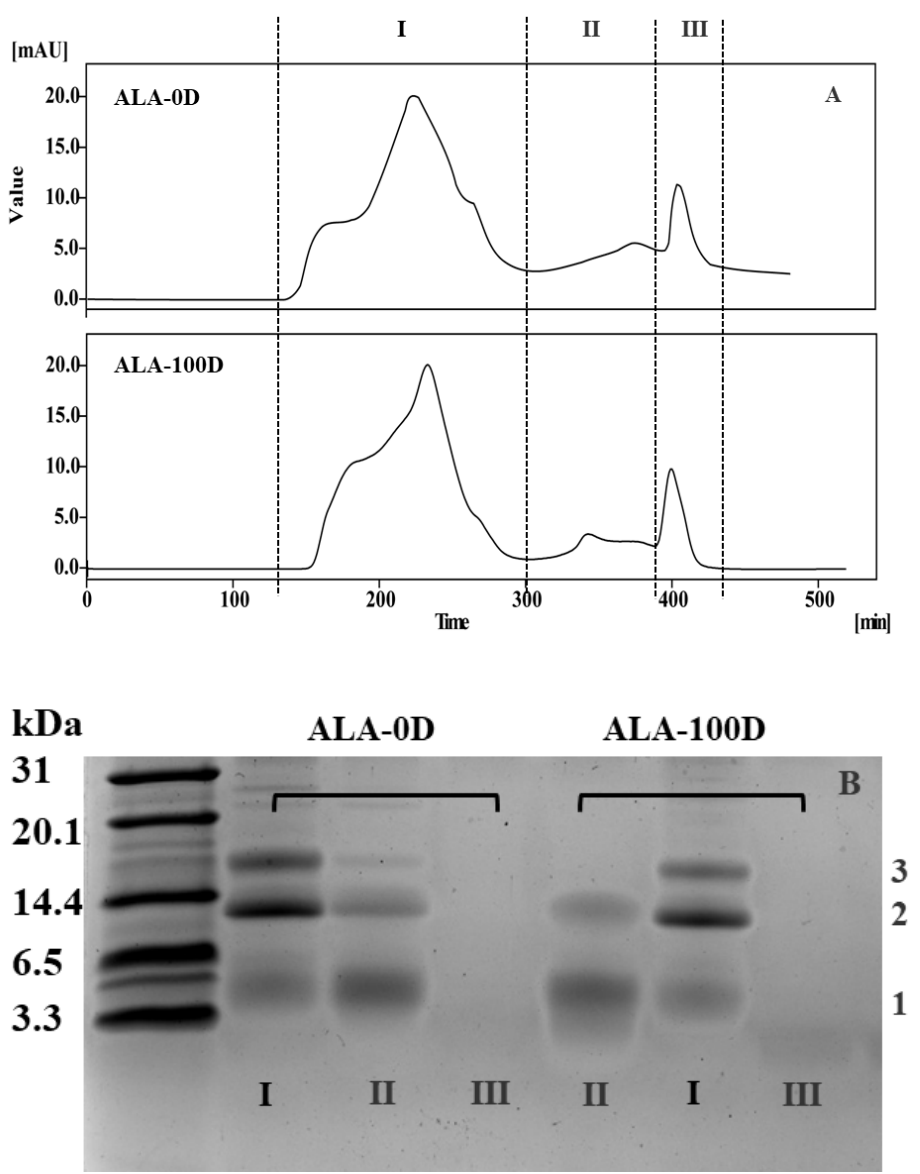

Figure 4. Isolation of ALA-0D and ALA-100D by Sephadex G-25 gel chromatography (A); the tricine SDS PAGE pattern of groups I, II, and III in ALA-100D and ALA-100D (B). ALA-0D and ALA-100D: untreated ALA and ultrasound-treated ALA at $100 \mathrm{~W} / \mathrm{cm}^{2}$ digested by simulated gastric juice followed simulated duodenal juice.

The results in Figure 3 showed that the anaphylaxis increased after gastroduodenal digestion, and ultrasound treatment raised the anaphylaxis ability of ALA after gastroduodenal digestion. Therefore, the KU812 degranulation assay for the three groups (I, II, and III) in ALA-0D and ALA-100D was performed. The release of histamine and IL-6 of each group is shown in Figure 5. The histamine release of group I in ALA-OD and ALA-100D was 8.37 and $8.21 \mu \mathrm{g} / \mathrm{L}$, and there was no significant difference between them. Compared with ALA-0D, the histamine release of group II in ALA-100D was 7.23 $\mu \mathrm{g} / \mathrm{L}$ and higher (Figure 5A). A similar phenomenon was observed in group III in ALA-0D and ALA-100D. That was to say, the cell degranulation of group III in ALA-100D was higher than that in ALA-0D $(p<0.05)$. When the KU812 cells were exposed to group I in ALA-D, the $\beta-\mathrm{Hex}$ release was $404.15 \mathrm{pg} / \mathrm{mL}$ and was lower than that of ALA-100D $(p<0.05)$. Furthermore, when it came to group II and III, the $\beta$-Hex release content of ALA-100D was higher than ALA-0D $(p<0.05)$ (Figure $5 \mathrm{~B})$. In general, gastroduodenal digesta groups still retained anaphylaxis, and groups II and III had a low release activity of bioactive mediators. However, they still retained anaphylaxis. 

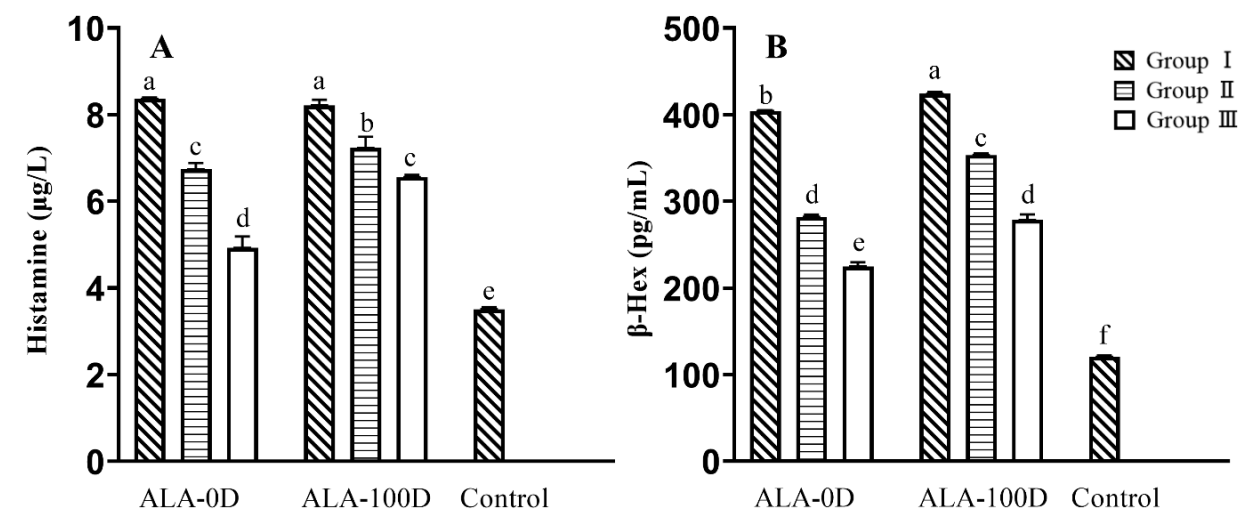

Figure 5. The KU812 cells degranulation of groups I, II, and III isolated from ALA-0D and ALA-100D. The release of histamine (A) and $\beta$-Hex (B). Letters (a-f) demonstrate significant differences $(p<0.05)$. ALA-0D and ALA-100D: untreated ALA and ultrasound-treated ALA at $100 \mathrm{~W} / \mathrm{cm}^{2}$ digested by simulated gastric juice followed simulated duodenal juice.

\subsection{Anti-Digestive Stable Peptides Identification}

The anti-digestive stable peptides of groups II and III in ALA-0D and ALA-100D were analyzed by HPLC-MS/MS. Figure 6A-D shows the MS and MS/MS spectra of peptides DTQAIVQNNDSTEY (AA 37-50) and KFLDDDLTDDIM (AA 79-90). The $m / z$ of AA 37-50 was 798.3477, and the peptide AA 37-50 was identified according to the difference between the values of $b$ and $y$ ions. The amino acid sequences of AA 79-90 and other peptides were identified in the same way. As shown in Table 1, it was found that 22 and 20 anti-digestive stable peptides were identified from group II in ALA-0D and ALA-100D, respectively, and identified peptides of group III in ALA-0D and ALA-100D were 16 and 10. However, it is difficult to assess if the differences on the number of identified peptides represent a significant difference on digestibility between ALA-0D and ALA-100D.These anti-digestive stable peptides of group II mainly distributed in 32-43 (32-43, 33-43, 36-43), 37-50 (37-44, 37-46, 37-49, 37-50, 37-49, 40-50, 41-50), 79-90 (79-90, 80-86, 80-90, 80-92, 81-90, 82-90, 84-90), 94-104 (94-103, 94-104, 95-103, 95-104, 96-103, 96-104), and 115-123. When it comes to group III, we found that the anti-digestive stable peptides mainly distributed in 37-50 (37-44, 37-46, 37-50, 38-50, 41-50), 79-90 (79-87, 79-90, 80-86, 80-90, 81-90, 82-90, 84-90), 94-104 (94-103, 94-104, 95-102, 95-103, 95-104, 96-104), 99-108 (99-107, 99-108). 99-107 (108) were only discovered in group III of ALA-100D. This might be ultrasound unfolded the structure of ALA, leading peptide bond 98-99 and 107-108 (108-109) to be hydrolyzed and formed peptide 99-107 and 99-108. Figure 7 shows the anti-digestive stable peptides in the 3D structure of ALA. It could be seen that most of the anti-digestive stable peptides were distributed on the $\alpha$-helix.

(A)

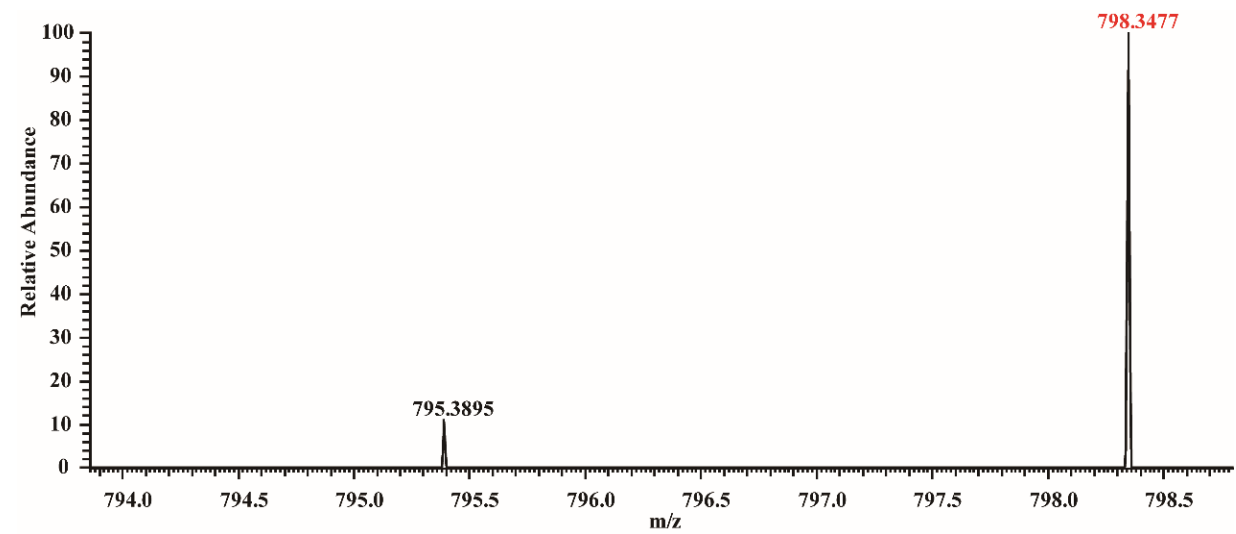

Figure 6. Cont. 
(B)

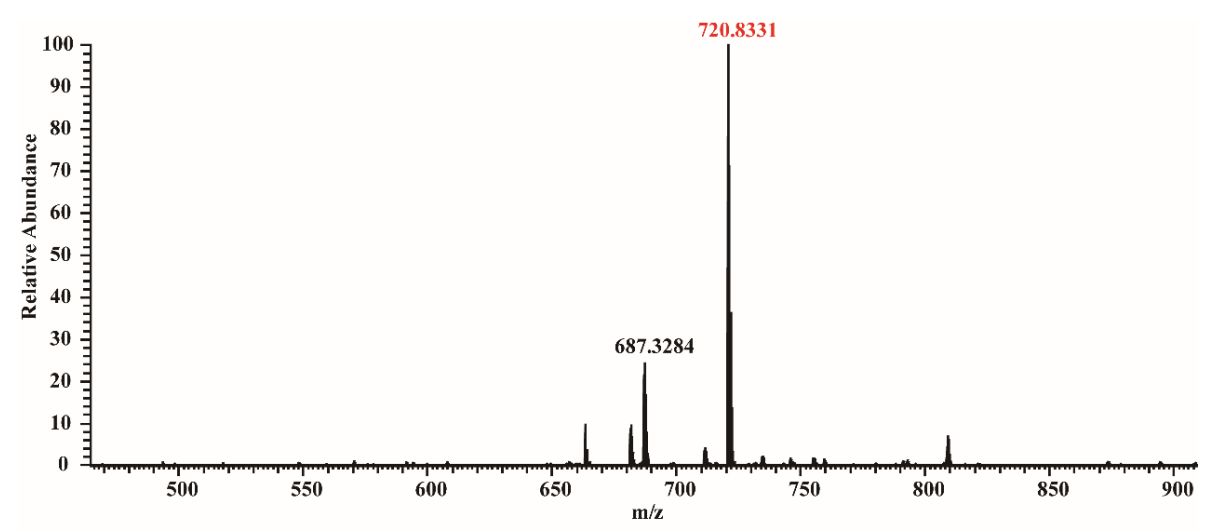

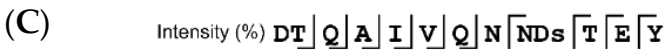
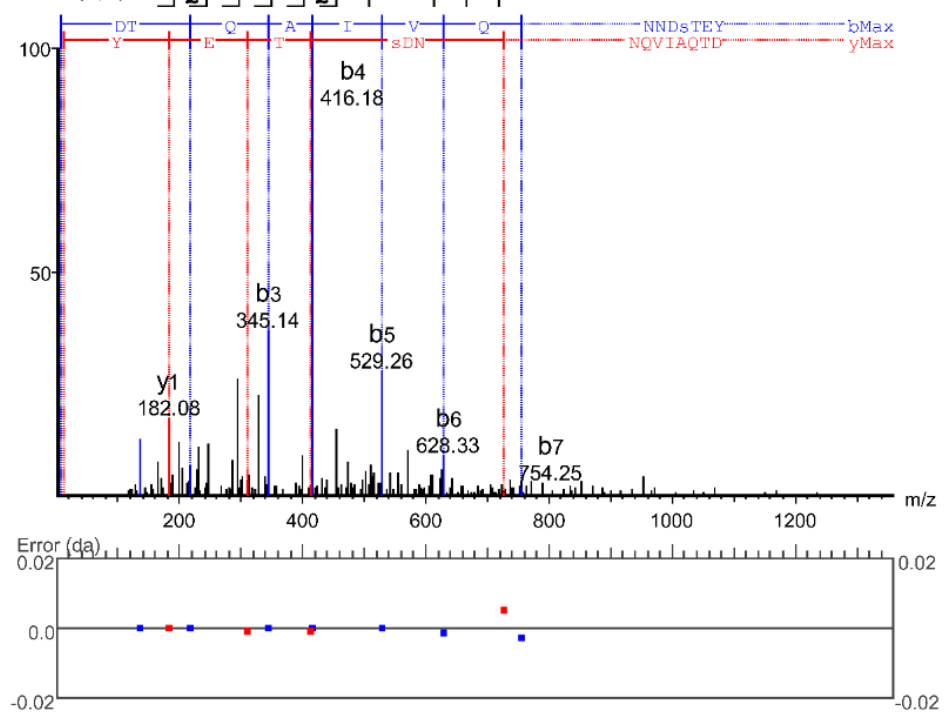

(D)
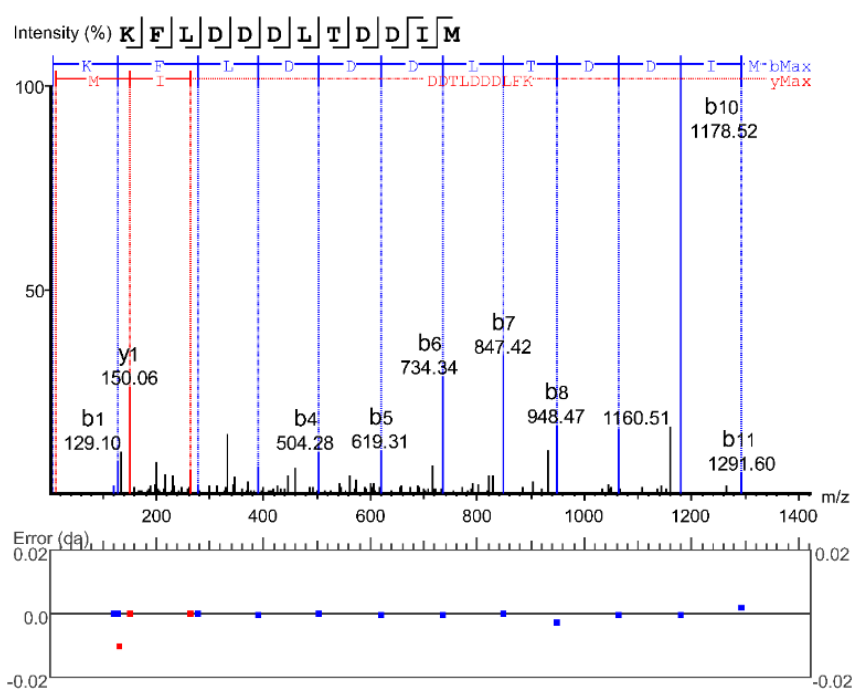

Figure 6. MS spectra of the anti-digestive stable peptides of DTQAIVQNNDSTEY and KFLDDDLTDDIM (A,C). HCD-MS/MS spectra of DTQAIVQNNDSTEY and KFLDDDLT$\operatorname{DDIM}(\mathbf{B}, \mathbf{D})$. 
Table 1. The anti-digestive stable peptides determined by high-performance liquid chromatography system coupled to tandem mass spectrometry (LC-MS/MS).

\begin{tabular}{|c|c|c|c|c|c|c|}
\hline Peptide & Mass & Length & ppm & $m / z$ & Start & End \\
\hline \multicolumn{7}{|c|}{ Group II in ALA-0D } \\
\hline GGVSLPEWV & 942.4811 & 9 & 1.4 & 472.2485 & 19 & 27 \\
\hline TSGYDTQAIVQ & 1181.5564 & 11 & 1.6 & 591.7864 & 33 & 43 \\
\hline YDTQAIVQ & 936.4553 & 8 & 0.2 & 469.235 & 36 & 43 \\
\hline DTQÄIVQN & 909.4168 & 8 & 0.1 & 455.7157 & 37 & 44 \\
\hline DTQAIVQNND & 1099.4781 & 10 & 1.5 & 550.7472 & 37 & 46 \\
\hline DTQAIVQNNNDSTE & 1433.6271 & 13 & 2.4 & 717.8225 & 37 & 49 \\
\hline DTQAAIVQNNDSTEY & 1618.6722 & 14 & 0.1 & 810.3435 & 37 & 50 \\
\hline AIVQNNDSTEY & 1274.5391 & 11 & -0.2 & 638.2767 & 40 & 50 \\
\hline IVQNNDSTEY & 1181.52 & 10 & -0.4 & 1182.5269 & 41 & 50 \\
\hline KFLDDDLTDDIM & 1421.6384 & 12 & 2.5 & 711.8282 & 79 & 90 \\
\hline FLDDDLT & 859.3575 & 7 & 0.3 & 430.6862 & 80 & 86 \\
\hline FLDDDLTDDI & 1162.5029 & 10 & 0.3 & 582.2589 & 80 & 89 \\
\hline FLDDDLTDDIM & 1333.536 & 11 & 0.1 & 667.7753 & 80 & 90 \\
\hline FLDDDLTDDIMCV & 1513.6316 & 13 & 0.1 & 757.8231 & 80 & 92 \\
\hline FLDDDLTDDIMCVKKI & 1966.9268 & 16 & 0.3 & 984.4709 & 80 & 95 \\
\hline LDDDLTDDIM & 1146.4751 & 10 & 0.8 & 574.2453 & 81 & 90 \\
\hline DDDLTDDIM & 1073.3835 & 9 & 1.9 & 537.7001 & 82 & 90 \\
\hline KILDKVGINY & 1161.6758 & 10 & -0.1 & 581.8451 & 94 & 103 \\
\hline ILDKVGINY & 1055.5627 & 9 & 0.7 & 1056.5708 & 95 & 103 \\
\hline ILDKVGINYW & 1219.66 & 10 & 1 & 610.8379 & 95 & 104 \\
\hline LDKVGINY & 920.4967 & 8 & 1 & 461.2561 & 96 & 103 \\
\hline LDQWLCEKL & 1146.5743 & 9 & 1.8 & 574.2955 & 115 & 123 \\
\hline \multicolumn{7}{|c|}{ Group III in ALA-0D } \\
\hline HTSGYDTQ & 907.3672 & 8 & 1.7 & 454.6906 & 32 & 39 \\
\hline DTQAIVQN & 869.4243 & 8 & 3 & 435.7197 & 37 & 44 \\
\hline DTQAIVQNND & 1138.4867 & 10 & -0.4 & 570.249 & 37 & 46 \\
\hline DTQAIVQNNDSTEY & 1618.6722 & 14 & -0.1 & 810.3413 & 37 & 50 \\
\hline TQAIVQNNDSTEY & 1498.6899 & 13 & 3 & 750.3527 & 38 & 50 \\
\hline IVQNNDSTEY & 1203.502 & 10 & 0.5 & 602.7571 & 41 & 50 \\
\hline GLFQINNK & 932.5079 & 8 & 3.1 & 467.2615 & 51 & 58 \\
\hline KFLDDDLTD & 1080.4974 & 9 & 4.9 & 541.2573 & 79 & 87 \\
\hline KFLDDDLTDDIM & 1455.6439 & 12 & 0.3 & 728.8277 & 79 & 90 \\
\hline FLDDDLTDDIM & 1333.536 & 11 & 0 & 667.7736 & 80 & 90 \\
\hline FLDDDLTDDIMCV & 1513.6316 & 13 & 2.3 & 757.823 & 80 & 92 \\
\hline LDDDLTDDIM & 1180.4806 & 10 & 3.2 & 591.248 & 81 & 90 \\
\hline DDDLTDDIM & 1051.4016 & 9 & 3.2 & 526.7085 & 82 & 90 \\
\hline DLTDDIM & 821.3477 & 7 & 3.6 & 822.3559 & 84 & 90 \\
\hline LDKVGIN & 870.5175 & 8 & 1.7 & 436.2657 & 95 & 102 \\
\hline ILDKVGINYW & 1220.644 & 10 & 4.7 & 611.3307 & 95 & 104 \\
\hline \multicolumn{7}{|c|}{ Group II in ALA-100D } \\
\hline ELKDLKGY & 946.5123 & 8 & 1.1 & 474.2639 & 11 & 18 \\
\hline HTSGYDTQAIVQ & 1319.5994 & 12 & -0.3 & 660.8068 & 32 & 43 \\
\hline TSGYDTQAIVQ & 1181.5564 & 11 & 1.5 & 591.7864 & 33 & 43 \\
\hline DTQAIVQN & 888.4189 & 8 & 0.9 & 445.2171 & 37 & 44 \\
\hline DTQAIVQNND & 1117.4888 & 10 & 0.4 & 559.7519 & 37 & 46 \\
\hline DTQAIVQNNDSTE & 1415.6165 & 13 & -0.9 & 708.8149 & 37 & 49 \\
\hline DTQAIVQNNDSTEY & 1634.6373 & 14 & 0 & 818.3259 & 37 & 50 \\
\hline TQAIVQNNDSTEY & 1481.6635 & 13 & 1.4 & 1482.6727 & 38 & 50 \\
\hline AIVQNNDSTEY & 1274.5391 & 11 & 0.1 & 638.2769 & 40 & 50 \\
\hline IVQNNDSTEY & 1203.502 & 10 & -0.4 & 602.758 & 41 & 50 \\
\hline KFLDDDLTDDIM & 1455.6439 & 12 & 1.5 & 728.8303 & 79 & 90 \\
\hline FLDDDLTDDIM & 1333.536 & 11 & 0.1 & 667.7753 & 80 & 90 \\
\hline FLDDDLTDDIMCV & 1529.6266 & 13 & -2.2 & 765.8189 & 80 & 92 \\
\hline LDDDLTDDIM & 1180.4806 & 10 & 0.7 & 591.248 & 81 & 90 \\
\hline KILDKVGINY & 1183.6577 & 10 & -0.4 & 1184.6646 & 94 & 103 \\
\hline KILDKVGINYW & 1369.7369 & 11 & 0.6 & 685.8762 & 94 & 104 \\
\hline ILDKVGINYW & 1219.66 & 10 & 1.1 & 610.838 & 95 & 104 \\
\hline
\end{tabular}


Table 1. Cont.

\begin{tabular}{|c|c|c|c|c|c|c|}
\hline Peptide & Mass & Length & ppm & $m / z$ & Start & End \\
\hline ILDKVGINY & 1033.5808 & 9 & 0.7 & 517.798 & 95 & 103 \\
\hline LDKVGINY & 921.4807 & 8 & 0.2 & 461.7477 & 96 & 103 \\
\hline LDQWLCEKL & 1146.5743 & 9 & 0.4 & 574.2947 & 115 & 123 \\
\hline \multicolumn{7}{|c|}{ Group III in ALA-100D } \\
\hline GYGGVSLPEWV & 1162.5658 & 11 & 1.3 & 582.291 & 17 & 27 \\
\hline DTQAIVQNNDSTEY & 1618.6722 & 14 & 1.8 & 810.3448 & 37 & 50 \\
\hline LDDDLTDDIM & 1333.536 & 11 & 0 & 667.7753 & 80 & 90 \\
\hline KILDKVGINY & 1143.6652 & 10 & 1.4 & 572.8406 & 94 & 103 \\
\hline KILDKVGINYW & 1363.75 & 11 & -0.6 & 682.8818 & 94 & 104 \\
\hline ILDKVGINY & 1032.5968 & 9 & 1.2 & 517.3063 & 95 & 103 \\
\hline ILDKVGINYW & 1235.655 & 10 & 0.7 & 618.8352 & 95 & 104 \\
\hline LDKVGINYW & 1106.576 & 9 & 0 & 554.2953 & 96 & 104 \\
\hline VGINYWLAH & 1071.5502 & 9 & 0.7 & 536.7827 & 99 & 107 \\
\hline VGINYWLAHK & 1200.6292 & 10 & 0.8 & 601.3223 & 99 & 108 \\
\hline
\end{tabular}

(A)

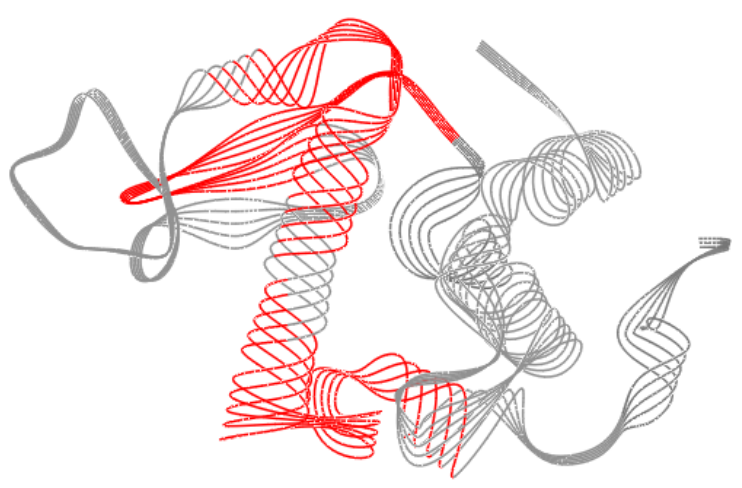

(B)

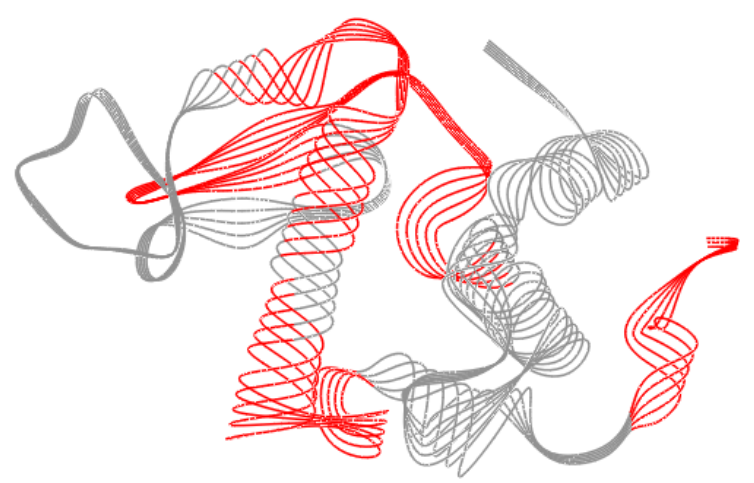

Figure 7. The 3D structure of ALA and the anti-digestive stable peptides of groups II (A) and III (B). The anti-digestive stable peptides are marked in red. Protein Data Bank (PDB) code: 1F6R. ALA: $\alpha$-lactalbumin.

Jarvinen et al. [36] found linear epitopes of ALA including AA 1-16, AA 13-26, AA 47-58, AA 93-102, AA 7-18, AA 51-61, AA 89-108. The anti-digestive stable peptides such as AA 94-104 and AA 99-108 detected by us were located in AA 93-102 and AA 89-108. Maynard et al. [37] identified AA 99-108, AA 17-58, AA 109-123, and AA 59-94 as the linear epitopes of ALA, and AA 37-50, AA 79-90 and AA 115-123 detected by us overlapped with some of the epitopes they identified. Li. et al. [38] found that linear epitopes of ALA were AA 37-46, AA 52-54, AA 56-59, and AA 63-72, AA 74-76, AA 81-90, AA 92-99, AA 41-46, AA 55-60, AA 62-72, AA 74-76, AA 85-90 and AA 92-99, and the linear epitopes such as AA 41-46, AA 85-90, AA 37-46, AA 81-90 remained intact on the anti-digestive stable peptides (AA 41-50, AA 80-92, AA 80-95, AA 81-90, AA 37-50, AA 81-90). Some linear epitopes are still retained on the anti-digestive stable peptides produced after gastroduodenal digestion, and these linear epitopes are exposed, resulting in increased anaphylaxis after digestion.

\section{Conclusions}

In this work, it was exhibited that ultrasound unfolded the structure of ALA, thereby increasing the $\operatorname{IgG} / \mathrm{IgE}$-binding abilities and also raising the release of the bioactive mediators. The anaphylaxis of untreated and ultrasound-treated ALA further increased after digestion, which might be that linear epitopes play an important role in affecting anaphylaxis compared with the conformational epitopes. Furthermore, some linear epitopes were still retained on the anti-digestive stable peptides produced after gastroduodenal 
digestion. Among gastric/gastroduodenal digesta, the digesta of ultrasound-treated ALA embodied high anaphylaxis. Therefore, ultrasound could increase the anaphylaxis of ALA during digestion.

Supplementary Materials: The following are available online at https:/ / www.mdpi.com/article/10 .3390 / foods10112760/s1, Table S1: The information of CMA patients' sera.

Author Contributions: Conceptualization, X.W. and H.W.; methodology, X.W.; software, X.W.; validation, H.W. and Z.T.; formal analysis, X.W.; investigation, X.W.; resources, H.W. and Z.T.; data curation, H.W.; writing —original draft preparation, X.W.; writing—review and editing, X.W., G.L., Y.H. and T.H.; visualization, X.W., G.L., Y.H. and T.H.; supervision, H.W.; project administration, H.W. and Z.T.; funding acquisition, H.W. and Z.T.; All authors have read and agreed to the published version of the manuscript.

Funding: This work was supported by China Postdoctoral Science Foundation (2020M682109), Jiangxi Provincial Natural Science Foundation (No. 20202BABL215027) and the Open Project Program of State Key Laboratory of Food Science and Technology, Nanchang University (No. SKLF-KF-202005).

Conflicts of Interest: The authors declare no conflict of interest.

\section{References}

1. Dong, X.; Wang, J.; Raghavan, V. Critical reviews and recent advances of novel non-thermal processing techniques on the modification of food allergens. Crit. Rev. Food Sci. 2020, 61, 196-210. [CrossRef] [PubMed]

2. Kadam, S.U.; Tiwari, B.K.; Álvarez, C.; O'Donnell, C.P. Ultrasound applications for the extraction, identification and delivery of food proteins and bioactive peptides. Trends Food Sci. Tech. 2015, 46, 60-67. [CrossRef]

3. Ma, S.; Wang, C.; Guo, M.R. Changes in structure and antioxidant activity of $\beta$-lactoglobulin by ultrasound and enzymatic treatment. Ultrason. Sonochem. 2018, 43, 227-236. [CrossRef]

4. Wu, Q.Y.; Zhang, X.F.; Jia, J.Q.; Kuang, C.; Yang, H.S. Effect of ultrasonic pretreatment on whey protein hydrolysis by alcalase: Thermodynamic parameters, physicochemical properties and bioactivities. Process Biochem. 2018, 67, 46-54. [CrossRef]

5. Dong, X.; Wang, J.; Raghavan, V. Effects of high-intensity ultrasound processing on the physiochemical and allergenic properties of shrimp. Innov. Food Sci. Emerg. 2020, 65, 102441. [CrossRef]

6. Yang, A.S.; Zuo, L.L.; Cheng, Y.F.; Wu, Z.H.; Li, X.; Tong, P.; Chen, H.B. Degradation of major allergens and allergenicity reduction of soybean meal through solid-state fermentation with microorganisms. Food Funct. 2018, 9, 1899-1909. [CrossRef]

7. Sicherer, S.H.; Sampson, H.A. Food allergy: Epidemiology, pathogenesis, diagnosis, and treatment. J. Allergy Clin. Immun. 2014, 133, 291-307. [CrossRef] [PubMed]

8. Tordesillas, L.; Berin, M.C.; Sampson, H.A. Immunology of food allergy. Immunity 2017, 47, 32-50. [CrossRef]

9. Meglio, P.; Bartone, E.; Plantamura, M.; Arabito, E.; Giampietro, P.G. A protocol for oral desensitization in children with IgE-mediated cow's milk allergy. Allergy 2015, 59, 980-987. [CrossRef] [PubMed]

10. Martin, C.R.; Ling, P.R.; Blackburn, G.L. Review of infant feeding: Key features of breast milk and infant formula. Nutrients 2016, 8, 279. [CrossRef]

11. Fiocchi, A.; Schünemann, H.J.; Brozek, J.; Restani, P.; Beyer, K.; Troncone, R.; Martelli, A.; Terracciano, L.; Bahna, S.L.; Rancé, F. Diagnosis and rationale for action against cow's milk allergy (DRACMA): A summary report. J. Allergy Clin. Immun. 2010, 126, 1119-1128. [CrossRef] [PubMed]

12. Luyt, D.; Ball, H.; Makwana, N.; Green, M.R.; Bravin, K.; Nasser, S.M.; Clark, A.T. BSACI guideline for the diagnosis and management of cow's milk allergy. Clin. Exp. Allergy 2014, 44, 642-672. [CrossRef]

13. Wal, J.M. Cow's milk allergens. Allergy 1998, 53, 1013-1022. [CrossRef] [PubMed]

14. Jambrak, A.R.; Mason, T.J.; Lelas, V.; Krešić, G. Ultrasonic effect on physicochemical and functional properties of $\alpha$-lactalbumin. LWT-Food Sci. Technol. 2010, 43, 254-262. [CrossRef]

15. Ma, L.; Li, A.; Li, T.Q.; Li, M.; Wang, X.D.; Hussain, M.A.; Qayum, A.; Jiang, Z.M.; Hou, J.C. Structure and characterization of laccase-crosslinked $\alpha$-lactalbumin: Impacts of high pressure homogenization pretreatment. LWT-Food Sci. Technol. 2020, 118, 108843. [CrossRef]

16. Qayum, A.; Hussain, M.; Li, M.; Li, J.Q.; Shi, R.J.; Li, T.Q.; Anwar, A.; Ahmed, Z.; Hou, J.C.; Jiang, Z.M. Gelling, microstructure and water-holding properties of alpha-lactalbumin emulsion gel: Impact of combined ultrasound pretreatment and laccase cross-linking. Food Hydrocoll. 2020, 110, 106122. [CrossRef]

17. Wang, C.; Xie, Q.; Wang, Y.B.; Fu, L.L. Effect of ultrasound treatment on allergenicity reduction of milk casein via colloid formation. J. Agric. Food Chem. 2020, 68, 4678-4686. [CrossRef] [PubMed]

18. Yuan, X.Y.; Li, X.Y.; Zhang, X.L.; Mu, Z.S.; Gao, Z.L.; Jiang, L.Z.; Jiang, Z.M. Effect of ultrasound on structure and functional properties of laccase-catalyzed $\alpha$-lactalbumin. J. Food Eng. 2018, 223, 116-123. [CrossRef]

19. Untersmayr, E.; Jensen-Jarolim, E. The role of protein digestibility and antacids on food allergy outcomes. J. Allergy Clin. Immun. 2008, 121, 1301-1308. [CrossRef] 
20. Dupont, D.; Mandalari, G.; Molle, D.; Jardin, J.; Léonil, J.; Faulks, R.M.; Wickham, M.S.; Clare Mills, E.N.; Mackie, A.R. Comparative resistance of food proteins to adult and infant in vitro digestion models. Mol. Nutr. Food Res. 2010, 54, 767-780. [CrossRef]

21. Tong, P.; Gao, J.Y.; Chen, H.B.; Li, X.; Zhang, Y.; Jian, S.; Wichers, H.; Wu, Z.H.; Yang, A.S.; Liu, F.H. Effect of heat treatment on the potential allergenicity and conformational structure of egg allergen ovotransferrin. Food Chem. 2012, 131, 603-610. [CrossRef]

22. Meng, X.Y.; Li, X.; Wang, X.K.; Gao, J.Y.; Yang, H.; Chen, H.B. Potential allergenicity response to structural modification of irradiated bovine $\alpha$-lactalbumin. Food Funct. 2016, 7, 3102-3110. [CrossRef]

23. Yang, W.H.; Tu, Z.C.; Wang, H.; Li, X.; Tian, M. High-intensity ultrasound enhances the immunoglobulin (Ig) G and IgE binding of ovalbumin. J. Sci. Food Agric. 2017, 97, 2714-2720. [CrossRef]

24. Cattaneo, S.; Stuknyte, M.; Masotti, F.; De Noni, I. Protein breakdown and release of $\beta$-casomorphins during in vitro gastrointestinal digestion of sterilised model systems of liquid infant formula. Food Chem. 2017, 217, 476-482. [CrossRef] [PubMed]

25. Yang, Y.P.; Liu, G.X.; Tu, Z.C.; Wang, H.; Hu, Y.M.; Mao, J.H.; Zhang, J.J. Insight into the Mechanism of Reduced IgG/IgE Binding Capacity in Ovalbumin as Induced by Glycation with Monose Epimers through Liquid Chromatography and High-Resolution Mass Spectrometry. J. Agric. Food Chem. 2020, 68, 6065-6075. [CrossRef] [PubMed]

26. De Carvalho, N.C.; Pessato, T.B.; Fernandes, L.G.R.; De Lima Zollner, R.; Netto, F.M. Physicochemical characteristics and antigenicity of whey protein hydrolysates obtained with and without $\mathrm{pH}$ control. Int. Dairy J. 2017, 71, 24-34. [CrossRef]

27. Cabanillas, B.; Maleki, S.J.; Rodriguez, J.; Burbano, C.; Muzquiz, M.; Jimenez, M.A.; Pedrosa, M.M.; Cuadrado, C.; Crespo, J.F. Heat and pressure treatments effects on peanut allergenicity. Food Chem. 2012, 132, 360-366. [CrossRef] [PubMed]

28. Wang, W.M.; Ye, Y.H.; Tu, Z.C.; Hu, Y.M.; Wang, H.; He, C.Y. Investigation of the mechanism underlying the influence of mild glycation on the digestibility and IgG/IgE-binding abilities of $\beta$-lactoglobulin and its digests through LC orbitrap MS/MS. LWT-Food Sci. Technol. 2021, 139, 110506. [CrossRef]

29. Fang, Y.; Pan, X.; Zhao, E.M.; Shi, Y.; Shen, X.C.; Wu, J.; Pei, F.; Hu, Q.H.; Qiu, W.F. Isolation and identification of immunomodulatory selenium-containing peptides from selenium-enriched rice protein hydrolysates. Food Chem. 2019, 275, 696-702. [CrossRef]

30. Shao, Y.H.; Zhang, Y.; Liu, J.; Tu, Z.C. Influence of ultrasonic pretreatment on the structure, antioxidant and IgG/IgE binding activity of $\beta$-lactoglobulin during digestion in vitro. Food Chem. 2020, 312, 126080. [CrossRef]

31. Huang, L.R.; Ding, X.N.; Dai, C.H.; Ma, H.L. Changes in the structure and dissociation of soybean protein isolate induced by ultrasound-assisted acid pretreatment. Food Chem. 2017, 232, 727-732. [CrossRef]

32. Hodgkinson, A.J.; Wallace, O.A.M.; Boggs, I.; Broadhurst, M.; Prosser, C.G. Gastric digestion of cow and goat milk: Impact of infant and young child in vitro digestion conditions. Food Chem. 2018, 245, 275-281. [CrossRef] [PubMed]

33. Gazme, B.; Rezaei, K.; Udenigwe, C.C. Effect of enzyme immobilization and in vitro digestion on the immune-reactivity and sequence of IgE epitopes in egg white proteins. Food Funct. 2020, 11, 6632-6642. [CrossRef] [PubMed]

34. Guimaraes, V.; Drumare, M.F.O.; Lereclus, D.; Gohar, M.; Lamourette, P.; Nevers, M.C.; Vaisanen-Tunkelrott, M.L.; Bernard, H.; Guillon, B.; Cre Minon, C. In vitro digestion of Cry1Ab proteins and analysis of the impact on their immunoreactivity. J. Agric. Food Chem. 2010, 58, 3222. [CrossRef]

35. Yu, W.; Freeland, D.M.H.; Nadeau, K.C. Food allergy: Immune mechanisms, diagnosis and immunotherapy. Nat. Rev. Immunol. 2016, 16, 751-765. [CrossRef]

36. Auml, J.; Rvinen, K.M.; Chatchatee, P.; Bardina, L.; Beyer, K.; Sampson, H.A. IgE and IgG Binding Epitopes on $\alpha$-Lactalbumin and $\beta$-Lactoglobulin in Cow's Milk Allergy. Int. Arch. Allergy Immunol. 2001, 126, 111-118.

37. Maynard, F.; Jost, R.; Wal, J.M. Human IgE binding capacity of tryptic peptides from bovine $\alpha$-lactalbumin. Int. Arch. Allergy Immunol. 2009, 113, 478-488. [CrossRef] [PubMed]

38. Li, X.; Yuan, S.L.; Huang, M.J.; Gao, J.Y.; Wu, Z.Y.; Tong, P.; Yang, A.S.; Chen, H.B. Identification of IgE and IgG epitopes on native Bos d 4 allergen specific to allergic children. Food Funct. 2006, 7, 2996-3005. [CrossRef] [PubMed] 